\title{
Chromosomal Imbalances in Diffuse Large B-Cell Lymphoma Detected by Comparative Genomic Hybridization
}

\author{
Mattias Berglund, M.Sc., Gunilla Enblad, M.D., Ph.D., Emma Flordal, M.Sc., Weng-Onn Lui, M.Sc., \\ Carin Backlin, Ph.D., Ulf Thunberg, Ph.D., Christer Sundström, M.D., Ph.D., Göran Roos, M.D., Ph.D., \\ Susanne V. Allander, M.D., Ph.D., Martin Erlanson, M.D., Ph.D., Richard Rosenquist, M.D., Ph.D., \\ Catharina Larsson, M.D., Ph.D., Svetlana Lagercrantz, M.D., Ph.D.
}

Department of Molecular Medicine (MB, EF, W-OL, SVA, CL, SL), Karolinska Hospital, Stockholm; Department of Oncology, Radiology, and Clinical Immunology, Section of Oncology (MB, GE, CB, UT) and Department of Genetics and Pathology (CB, CS, RR), Rudbeck Laboratory, Uppsala University, Uppsala; and Department of Medical Biosciences, Pathology (GR), Department of Radiation Sciences, Oncology (ME), Umeå University, Umeå, Sweden

\begin{abstract}
Diffuse large B-cell lymphoma (DLBCL) is the most common form of non-Hodgkin lymphoma. In contrast to many other hematological malignancies, no chromosomal abnormalities with a diagnostic or prognostic value have been identified in DLBCL. Numerical chromosomal imbalances were characterized by comparative genomic hybridization (CGH) performed on 54 DLBCL tumors from a total of 40 patients. The clonal relatedness was demonstrated in 9 of 11 pairs of matched diagnostic tumors and their relapses as determined by IGH gene rearrangement analysis and/or the CGH profiles. Furthermore, immunohistochemical expression analyses of BCL2 and BCL6/LAZ3 were performed on all cases. Copy number changes were detected in 94\% of the diagnostic tumor samples and in all of the relapses. Chromosomal losses in diagnostic tumors were preferentially observed at 8p22-pter (29\%), 1p34-pter (26\%), 6q23-qter (20\%), 17p12pter $(17 \%)$ and $22 q(17 \%), 9 p 23-p t e r(14 \%)$, whereas gains were mainly seen in Xq25-26 (43\%), $13 q 22$ (26\%), 12cen-q14 (20\%), 3q24-25 (11\%), 7 (11\%), and 18q12-21 (11\%). Loss of 22q was significantly more commonly seen in the diagnostic tumor samples with more advanced clinical stage in other
\end{abstract}

Copyright (C) 2002 by The United States and Canadian Academy of Pathology, Inc.

VOL. 15, NO. 8, P. 807, 2002 Printed in the U.S.A.

Date of acceptance: April 1, 2002.

Supported by grants from the Swedish Cancer Foundation, the Jeanssons Foundation, the Torsten and Ragnar Söderberg Foundation, the Lions Cancer Research Foundation, the Selanders Foundation, the David \& Astrid Hagelén Foundation, the Knut and Alice Wallenberg Foundation, the Magn. Bergwall Foundation, and the Åke Wiberg Foundation.

Address reprint requests to: Mattias Berglund, M.Sc., Department of Molecular Medicine, Karolinska Hospital, CMM L8:01, SE-171 76, Stockholm, Sweden; e-mail: mattias.berglund@cmm.ki.se; fax: 46851776180.

DOI: 10.1097/01.MP.0000024375.04135.2B words, Stage III-IV compared with Stage I-II, and band 18q21 was significantly more often gained in relapses as compared to diagnostic tumors. None of the recurrent alterations were detected as a single abnormality, suggesting that other genetic lesions below the detection level of CGH may be the initiating event in the tumorigenesis of DLBCL. However, the distribution of CGH alterations support the idea of a progression of genetic events where loss of $8 p$ and $9 p$ and gain of $3 q, 13 q$, and $18 q$ would represent/relatively early events because they were distributed in tumors with only two abnormalities.

KEY WORDS: Chromosome, CGH, Clonality DLBCL. Mod Pathol 2002;15(8):807-817

Non-Hodgkin lymphomas (NHL) constitute a heterogeneous group of lymphoid neoplasms that display different morphological, immunological, cytogenetic, and molecular genetic features. The revised European-American classification of lymphoma (1) takes all these features into consideration for the distinction of different lymphoma entities. Lymphomas have been associated with a wide range of recurrent chromosomal abnormalities. Some of these can occur as a single cytogenetic alteration and may sometimes be recurrent in a lymphoma entity, such as the $\mathrm{t}(14 ; 18)(\mathrm{q} 32 ; \mathrm{q} 21)$, which is found in 85 to $90 \%$ of follicular lymphomas. The occurrence of distinct chromosomal changes in specific histopathological subtypes of NHL has improved the understanding of the genetic basis of lymphomagenesis (2).

Diffuse large B-cell lymphomas (DLBCL) constitute approximately $40 \%$ of all lymphomas and are typically characterized by an aggressive behavior in 
TABLE 1. Clinical Data of the 40 Cases of Diffuse Large B-Cell Lymphomas

\begin{tabular}{|c|c|c|c|c|c|c|}
\hline \multicolumn{2}{|c|}{ Case } & \multirow{2}{*}{$\begin{array}{c}\text { Age at } \\
\text { Diagnosis }\end{array}$} & \multirow{2}{*}{$\begin{array}{c}\text { Sex } \\
(M / F)\end{array}$} & \multirow{2}{*}{$\begin{array}{l}\text { Clinical } \\
\text { Stage* }^{*}\end{array}$} & \multicolumn{2}{|c|}{ Tumors Analyzed } \\
\hline No. & ID & & & & Diagnostic & Relapse \\
\hline 1 & A & 21 & $\mathrm{M}$ & IVB & + & - \\
\hline 2 & $\mathrm{~B}$ & 44 & $\mathrm{~F}$ & IIIA & + & - \\
\hline 3 & $\mathrm{C}$ & 57 & $\mathrm{M}$ & IAE & + & - \\
\hline 4 & $\mathrm{D}$ & 80 & M & IIIB & + & - \\
\hline 5 & $\mathrm{E}$ & 49 & $\mathrm{M}$ & IVB & + & - \\
\hline 6 & $\mathrm{~F}$ & 42 & M & IA & + & - \\
\hline 7 & 229 & 62 & $\mathrm{~F}$ & IA & + & - \\
\hline 8 & 239 & 72 & M & IVA & + & - \\
\hline 9 & 433 & 64 & $\mathrm{~F}$ & IA & + & - \\
\hline 10 & 542 & 45 & $\mathrm{M}$ & IA & + & - \\
\hline 11 & 877 & 72 & M & IAE & + & - \\
\hline 12 & 878 & 46 & $\mathrm{~F}$ & IIIB & + & - \\
\hline 13 & 228 & 54 & M & IIIA & + & - \\
\hline 14 & $\mathrm{~K}$ & 71 & M & IVB & + & - \\
\hline 15 & $\mathrm{~L}$ & 74 & $\mathrm{~F}$ & IVA & + & - \\
\hline 16 & $\mathrm{M}$ & 38 & $\mathrm{~F}$ & IVB & + & - \\
\hline 17 & 74 & 71 & $\mathrm{~F}$ & IAE & + & - \\
\hline 18 & 222 & 71 & M & IVB & + & - \\
\hline 19 & 790 & 75 & $\mathrm{M}$ & IVB & + & - \\
\hline 20 & 661 & 47 & $\mathrm{M}$ & IIB & + & - \\
\hline 21 & 413 & 62 & $\mathrm{M}$ & IIIB & + & - \\
\hline 22 & 288 & 54 & $\mathrm{M}$ & IIA & + & \\
\hline 23 & 577 & 48 & $\mathrm{M}$ & IVA & + & \\
\hline 24 & 657 & 56 & $\mathrm{~F}$ & IV & + & \\
\hline 25 & 852 & 44 & $\mathrm{~F}$ & IVB & + & \\
\hline 26 & G & 67 & $\mathrm{M}$ & IIIA & + & + \\
\hline 27 & $\mathrm{H}$ & 60 & $\mathrm{~F}$ & IIB & + & \\
\hline 28 & I & 52 & $\mathrm{M}$ & IVA & + & \\
\hline 29 & $\mathrm{~N}$ & 25 & $\mathrm{M}$ & IIIB & + & \\
\hline 30 & S & 47 & $\mathrm{M}$ & IIA & + & + \\
\hline 31 & 612 & 63 & $\mathrm{M}$ & IAE & + & + \\
\hline 32 & $\mathrm{~J}$ & 65 & M & IVA & + & + \\
\hline 33 & 454 & 69 & $\mathrm{~F}$ & IIIB & + & + \\
\hline 34 & 425 & 65 & $\mathrm{~F}$ & IVA & + & \\
\hline 35 & $\mathrm{O}$ & 50 & M & IA & + & \\
\hline 36 & $\mathrm{R}$ & 54 & $\mathrm{M}$ & IVB & - & + \\
\hline 37 & 471 & 61 & $\mathrm{M}$ & IIIB & - & + \\
\hline 38 & 574 & 66 & $\mathrm{M}$ & IA & - & + \\
\hline 39 & 836 & 69 & M & IIAE & & 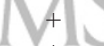 \\
\hline 40 & 633 & 64 & $\mathrm{M}$ & $\mathrm{IAE}^{12}$ & & \\
\hline
\end{tabular}

Clinical staging based on the involvement of one lymph node (I), $>1$ lymph node on the same side of the diaphragm (II), >1 lymph node on both sides of the diaphragm (III), and disease with bone marrow infiltration (IV).

$\mathrm{M} / \mathrm{F}=$ male/female; A refers to A-symptoms and B to B-symptoms $\mathrm{E}=$ extra nodular neoplasia

which less than half of the patients are cured (3). Despite intensified treatment with chemotherapy and radiotherapy, no real improvement of the clinical handling and survival have been achieved in the last 20 years. The clinical presentation and the course of the disease are extremely heterogeneous. Information regarding the chromosomal alterations found in DLBCL has come from regular cytogenetics $(2,4)$ as well as from analyses using comparative genomic hybridization (CGH) (5). Gains were preferentially identified for chromosomes $\mathrm{X}, 3,7,11,12$, and 18, whereas losses involved chromosomes X, 4, 6 , and 8. Translocations involving the BCL6/LAZ3 gene at $3 \mathrm{q} 27$ and BCL2 at $18 \mathrm{q} 21$ are found in 25 to $40 \%$ and 25 to $50 \%$ of the cases, respectively (6). The most common translocations, $\mathrm{t}(3 ; 14)$ and $\mathrm{t}(14 ; 18)$, appear in $20 \%$ and $30 \%$ of the cases, respectively
(7). In lymphomas with these translocations, BCL6 and $B C L 2$ expression is deregulated as a result of their juxtaposition to the $I G H$ gene at $14 \mathrm{q} 32$ (8). Increased expression of $B C L 2$ has also been shown to result from gene amplification (9). Genetic alterations involving the BCL6 gene are mainly associated with DLBCL, and in addition to the $t(3 ; 14)$, translocations between $B C L 6$ and a variety of chromosomes have been observed (10). BCL6 is usually expressed in normal B- and CD4-positive T-cells in the germinal center (GC), and helps to control the GC function (11-13). However, it is still not known whether BCL6 overexpression provides survival benefit for the DLBCL cells.

So far, the genetic mechanisms behind the clinical heterogeneity of DLBCL are poorly understood. To approach this question, we have analyzed a large panel of diagnostic tumor samples and relapses of DLBCL with regard to the distribution of unbalanced chromosomal aberrations that are possibly involved in tumor progression as well as their clonal relationship.

\section{MATERIALS AND METHODS}

\section{Patients and Tumor Specimens}

A total of 54 DLBCL specimens were obtained from 40 patients, 28 men and 12 women, diagnosed between 1985 and 1998 (Table 1). The patients were identified from the files of the Departments of Pathology at the Uppsala University Hospital, and the Umeà University Hospital, Sweden. For 10 cases, tumor material was available from both the diagnostic sample of DLBCL (D) and from subsequent relapses (R). Frozen tumor biopsies were available for all patients, and paraffin-embedded tumor material was available from all tumors except 11D, 13D, 19D, 20D, 25D, 34R1, 34R2, and 40R2. All tumors were reevaluated by histopathological analyses performed by two of the authors (CS and GR) and were confirmed to be DLBCL according to the revised European-American lymphoma classification (1). The term diagnostic tumor refers to the first sample obtained from each of the 40 patients which at histopathological examination was classified as DLBCL.

\section{Comparative Genomic Hybridization}

High molecular weight DNA was prepared from fresh frozen tumor tissue using a standard protocol for phenol-chloroform extraction, and the quality and concentrations of the samples were verified by agarose gel electrophoresis. CGH was performed as previously described $(14,15)$ with minor modifications. In brief, tumor DNA samples were labeled with fluorescein isothiocyanate (FITC)- 12-dUTP 


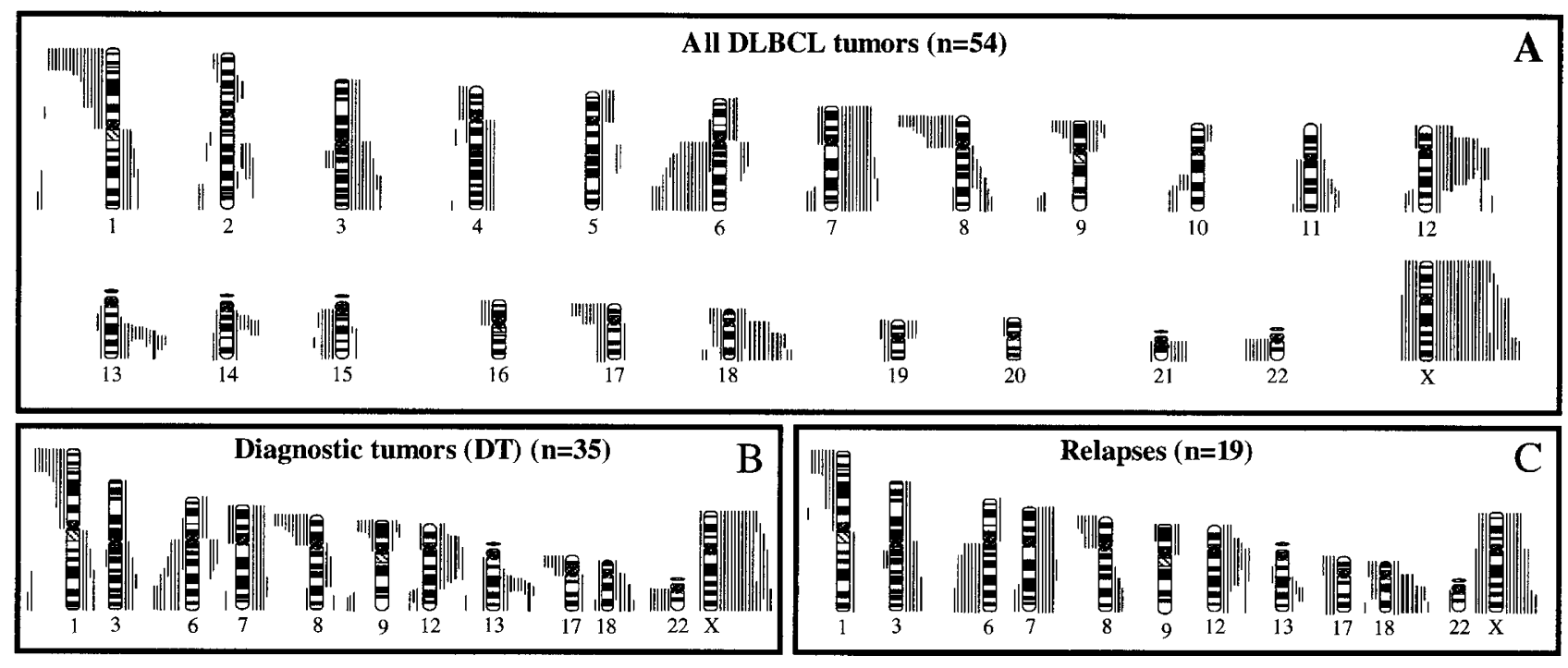

FIGURE 1. Copy number changes in 54 diffuse large B-cell lymphomas (DLBCL) from 40 patients. Each line represents one alteration detected in one tumor, with losses indicated to the left and gains to the right of the ideograms. Thick lines indicate high-level amplifications. A, all comparative genomic hybridization alterations detected in the entire material. The most commonly involved chromosomes in (B) diagnostic tumors, (C) relapses. $\mathrm{n}$, the total number of tumors analyzed in each category.

(Dupont, Boston, MA) by nick translation. Equivalent amounts (300-500 ng) of tumor and normal reference DNA labeled with Texas Red (Vysis, Inc.) were mixed together with unlabeled Cot-1-DNA (Vysis, Inc.), denatured and applied to slides with denatured metaphases of normal lymphocytes $(\mathrm{Vy}$ sis, Inc.). After hybridization at $37^{\circ} \mathrm{C}$ for $48 \mathrm{~h}$, the slides were washed in $0.4 \times$ standard saline citrate (SSC) $/ 0.3 \%$ Nonidet P- 40 at $74 \pm 1^{\circ} \mathrm{C}$ for 2 minutes, in $2 \times \mathrm{SSC} / 0.1 \%$ Nonidet $\mathrm{P}-40$ at room temperature for 2 minutes, and in sterile autoclaved water for 2 minutes. After air drying, slides were counterstained with 4,6-diamidino-2-phenylindole (DAPI, Vysis, Inc; $125 \mathrm{ng} / \mathrm{mL}$ ). Two control experiments were performed in which DNA from a healthy male donor was hybridized against normal reference male DNA, and DNA from a breast cancer cell-line (MPE600, Vysis, Inc) was hybridized against normal reference female DNA.

In the subsequent digital image analyses, 8 to 11 three-color digital images (DAPI, FITC, and Texas Red fluorescence) were captured from each hybridization using an Axioplan 2 epifluorescence microscope (Carl Zeiss Jena GmbH, Jena, Germany) and Sensys charge-coupled equipped (CCD) camera (Photometrics) interfaced to an IPLab Spectrum 10 workstation (Signal Analytics Corp., Vienna, VA). Relative DNA sequence copy number changes were detected by analyzing the hybridization intensities of tumor and normal DNA along the length of all chromosomes in each metaphase spread. The absolute fluorescence intensities were normalized so that the average green to red ratio of all chromosomes in each metaphase was 1.0. The final results were plotted as a series of green to red ratio profiles and corresponding standard deviation for each human chromosome from p- to q-telomere. At least 12 ratio profiles were averaged for each chromosome (except for $\mathrm{X}$ and $\mathrm{Y}$ ) to reduce noise. Green to red ratios $>1.2$ were considered as gains and ratios less than 0.8 as losses. The cut-off values were based on the average value from the whole material. Overrepresentation was considered as high-level amplifications when the ratio exceeded 2.0. Heterochromatic regions in the centromeric and paracentromeric parts of the chromosomes, the short arm of the acrocentric chromosomes, the Y chromosome, as well as all regions next to the telomeres were not included in the evaluation. As an internal control of the CGH methodology, six of the tumor samples were hybridized and analyzed on two different occasions, giving concordant results in all cases.

\section{Analyses of Clonal Relationship}

The consensus primers used for detection of IGHrearrangements and the PCR conditions have been described previously $(16,17)$. To distinguish monoclonal PCR products from polyclonal, single-stranded conformation polymorphism (SSCP), analysis was performed as reported elsewhere (18). In one case for which a clonal PCR product was lacking in the diagnostic tumor (Case 33), further analyses were carried out using Southern blotting and hybridization with a $\mathrm{J}_{\mathrm{H}}$ probe to determine clonality of the $I G H$ gene as previously detailed (19). Cases with changed SSCP pattern at relapse, but displaying one or several identical bands in common with the diagnostic tumor, were considered as clonally related, whereas divergent banding pattern be- 
TABLE 2. Findings by CGH and Immunohistochemistry in the 54 Diffuse Large B-cell Lymphoma samples Analyzed in the Study

\begin{tabular}{|c|c|c|c|c|}
\hline \multirow{2}{*}{ Tumor } & \multirow{2}{*}{ No. of Changes } & \multirow{2}{*}{ CGH Alterations* } & \multicolumn{2}{|c|}{ Immunohistochemistry } \\
\hline & & & BCL2 & BCL6 \\
\hline $1 \mathrm{D}$ & 12 & $\begin{array}{l}+ \text { Xp21-qter, - 1p34-pter, +2q22-32,+4q, +5q14-22,+6c-q16,+8q13-22,-9q33-qter, } \\
-12 q 23 \text {-qter, }+13 q 21-22,+14 q 13-22,-22 q\end{array}$ & 0 & 0 \\
\hline 2D & 7 & $+1 q 23-31,+7,+12$ pter-q21,+13q22-31,+14q13-22,+18q, $-22 q$ & 2 & 2 \\
\hline $3 \mathrm{D}$ & 7 & -1 p32-pter, $+5,+6 p,-6 q,+11 q,+13 q 14$-qter, $-19 p$ & 2 & 1 \\
\hline $4 \mathrm{D}$ & 12 & $\begin{array}{l}-1 \text { p34-pter, }+2 q 22-32,+3 q 23-25,+4 q,+5 q 14-23,+6 c-q 22,+9 p,+13 q 21-22, \\
-15 q 22-24,-16 p,-19,-22 q\end{array}$ & 0 & 1 \\
\hline $5 \mathrm{D}$ & 7 & + Xp21-pter, +Xq23-qter, +1q, +12p11.2-q21,+13q21-qter, $+18 q 22-q t e r,+21 q$ & 2 & 1 \\
\hline $6 \mathrm{D}$ & 3 & $+\mathrm{X},+14 \mathrm{q} 13-22,-16 \mathrm{p}$ & 1 & 1 \\
\hline $7 \mathrm{D}$ & 4 & $+\mathrm{X},-1 \mathrm{q} 41$-qter, $-2 \mathrm{q} 33$-qter, $-17 \mathrm{p}$ & 2 & 1 \\
\hline $8 \mathrm{D}$ & 0 & & 1 & 0 \\
\hline 9D & 3 & -6q21-qter,-8p22-pter,-9p23-pter & 0 & 2 \\
\hline $10 \mathrm{D}$ & 8 & $+X,+2 p 13-21,+2 q 32-33,-3 q 13.1-21,-6 q 23-q t e r,-7 p,+9 p 23-p t e r,+12 p 12-q 21$ & 1 & 2 \\
\hline $11 \mathrm{D}$ & 4 & $+\mathrm{X},-7 \mathrm{p},-8 \mathrm{p} 21-\mathrm{pter},+19 \mathrm{p}$ & $\operatorname{lm}$ & $\operatorname{lm}$ \\
\hline $12 \mathrm{D}$ & 4 & $-6 q,+11 q 14$-qter, $-17 p 12$-pter, $-22 q$ & 0 & 1 \\
\hline $13 \mathrm{D}$ & 7 & +1q31-qter,-2p23-pter,-4q13-21,-8p12-pter, +11q22-23,+12p11-q21,-18q22-qter & $\operatorname{lm}$ & $\operatorname{lm}$ \\
\hline $14 \mathrm{D}$ & 2 & $+12 q 24,+13 q 21-q t e r$ & 1 & 0 \\
\hline $15 \mathrm{D}$ & 3 & -2 p16-pter, $-9 \mathrm{p},+12 \mathrm{p} 12-\mathrm{q} 14$ & 1 & 2 \\
\hline $16 \mathrm{D}$ & 5 & $-6 q 15-22,+7 q 31-34,-8 p,+15 q 21,+18 p t e r-q 21$ & 0 & 0 \\
\hline $17 \mathrm{D}$ & 2 & $+2 p 13-16,+2 q 22-24$ & 0 & 2 \\
\hline $18 \mathrm{D}$ & 14 & $\begin{array}{l}-2 q 14-21,+2 q 24-35,+6 c-q 21,-6 q 22-q t e r,-8 p,-8 q 23-q t e r,-9 q 34,+9 p 21-23 \\
+11 q 14-22,-11 q 24-q t e r,+13 q 21-31,-17 p 12-\text { pter, }-18,-19\end{array}$ & 0 & 1 \\
\hline $19 \mathrm{D}$ & 5 & $+\mathrm{X},+7,-9 \mathrm{p} 21$-pter, $+11,-17 \mathrm{p} 12$-pter & $\operatorname{lm}$ & $\operatorname{lm}$ \\
\hline $20 \mathrm{D}$ & 1 & +8 cen-q22 & $\operatorname{lm}$ & $\operatorname{lm}$ \\
\hline $21 \mathrm{D}$ & 2 & -8p22-pter,-9p23-pter & 1 & 2 \\
\hline $22 \mathrm{D}$ & 2 & -1 q31-qter, +3 & 0 & 1 \\
\hline $23 \mathrm{D}$ & 3 & + Xp11.3-q26,-8p22-pter,-9p22-pter & 1 & 1 \\
\hline $24 \mathrm{D}$ & 7 & $+3 q 13.3$-qter, $-4 p,+4 q,-12 p,-13 q,-17 p,+17 q$ & 2 & 0 \\
\hline $25 \mathrm{D}$ & 0 & & $\operatorname{lm}$ & $\operatorname{lm}$ \\
\hline $26 \mathrm{D}$ & 7 & + Xq24-qter, $-1 p,+3 q,+5 p,+8 q 24$-qter, $-15 q,+18 q 12$-qter & 2 & 0 \\
\hline 26R & 6 & + Xq24-qter, $-1 p,+5 p,+8 q 23$-qter, $+14 q,+18 q 12$-qter & 2 & 0 \\
\hline $27 \mathrm{D}$ & 4 & $+\mathrm{X},-1 \mathrm{p} 31$-pter,-9q32-qter, $-12 \mathrm{q} 22-24$ & 0 & 1 \\
\hline 27R & 4 & $-X,-6 q,+12 q,+18 q 22-q$ ter & 0 & 1 \\
\hline $28 \mathrm{D}$ & 7 & $+\mathrm{X},-1 \mathrm{p} 34$-pter,-8p21-pter, +12c-q21,+13q21-22,+14q12-21,-22q & 0 & 0 \\
\hline 28R & 7 & $+\mathrm{Xq},+3,-6 \mathrm{q},-8 \mathrm{p} 21$-pter $,+12 \mathrm{c}-\mathrm{q} 21,+13 \mathrm{q} 21-22,+18 \mathrm{q} 12$-qter & 0 & 0 \\
\hline $29 \mathrm{D}$ & 3 & $+\mathrm{X},-12 \mathrm{q} 22$-qter, $-22 \mathrm{q}$ & 0 & 0 \\
\hline $29 \mathrm{R}$ & 1 & $-\mathrm{X}$ & 0 & 0 \\
\hline $30 \mathrm{D}$ & 4 & $+X q,-1 p 34-p t e r,-8 p,+13 q 21-22$ & 0 & 1 \\
\hline $30 \mathrm{R}$ & 6 & $+X q,-1 p 34-p t e r,+3 q 24-q t e r,-6 q 14-q t e r,-8 p,+18 q 12-21$ & 2 & 2 \\
\hline $31 \mathrm{D}$ & 3 & $+\mathrm{X},-7 \mathrm{q} 32$-qter,-14q22-qter & 0 & 0 \\
\hline $31 \mathrm{R}$ & 9 & + Xq25-qter,-2q22-24,+5p,-7q31-qter,-14q,+15q21-qter, $-17 p,-18 p,-20 p-1$ & 1 & 0 \\
\hline $32 \mathrm{D}$ & 11 & $\begin{array}{l}-1 \mathrm{p},-2 \mathrm{q} 33 \text {-qter, }-4 \text { pter-q21,-6p21-q21,+7,+10p12-pter,-10q23-qter, }-11 \mathrm{q} \\
+12 \text { pter-q21,+14q12-21,+21q }\end{array}$ & 2 & 0 \\
\hline $32 \mathrm{R}$ & 10 & $+\mathrm{X},-1 \mathrm{p} 32$-pter, $+7,+10 \mathrm{p} 12$-pter,-10q23-qter,-11q, +12p12-q21,+14q12-21,+21q, $-22 \mathrm{q}$ & 2 & 2 \\
\hline $33 \mathrm{D}$ & 5 & $-X,+1 q,-4 p,+6 p,-6 q 23-q t e r$ & 2 & 0 \\
\hline 33R & 4 & $-X,+1 q,+6 p,-6 q 23-q$ ter & 0 & 0 \\
\hline $34 \mathrm{D}$ & 8 & $+\mathrm{X},-1 \mathrm{p} 21$-pter, $-6 \mathrm{q},+7,-10 \mathrm{q} 22-23,-15 \mathrm{q},-16 \mathrm{p},-17 \mathrm{p}=\mathrm{C}$ & 2 & 2 \\
\hline $34 \mathrm{R} 1$ & 11 & $+\mathrm{X},-1 \mathrm{p} 21$-pter, $-3 \mathrm{q} 13.1-21,-6 \mathrm{q},+7,-10 \mathrm{q} 22-23,-15 \mathrm{q},-17,-18$ pter-q21,+19p, +21q & $\operatorname{lm}$ & $\operatorname{lm}$ \\
\hline $34 \mathrm{R} 2$ & 11 & $+\mathrm{X},-1 \mathrm{p} 21$-pter, $-3 \mathrm{q} 13.1-21,-6 \mathrm{q},+7,-10 \mathrm{q} 22-23,-15 \mathrm{q},-17,-18$ pter-q21, $+19 \mathrm{p},+21 \mathrm{q}$ & $\operatorname{lm}$ & $\operatorname{lm}$ \\
\hline $35 \mathrm{D}$ & 2 & $-8 p,+18 q$ & 2 & 1 \\
\hline $35 \mathrm{R} 1$ & 2 & $-8 \mathrm{p},+\mathbf{1 8 q}$ & 2 & 1 \\
\hline $35 \mathrm{R} 2$ & 5 & -1 p34-pter, $-6 q 14$-qter, $-8 p,+9 p,+18 q$ & 2 & 1 \\
\hline $35 \mathrm{R} 3$ & 4 & $-1 p 34-$ pter $,-8 p,+9 p,+\mathbf{1 8 q}$ & 2 & 1 \\
\hline $36 \mathrm{R}$ & 3 & -9 p21-pter, $+12,+13 q 21-q t e r$ & 2 & 1 \\
\hline $37 \mathrm{R}$ & 5 & $+\mathrm{X},+7,+8 \mathrm{q} 22$-qter, +12pter-q21,-18q22-qter & 2 & 2 \\
\hline $38 \mathrm{R}$ & 4 & $-X q,-6 q,+7,+12 p 12-q 21$ & 0 & 2 \\
\hline $39 \mathrm{R}$ & 13 & $\begin{array}{l}+\mathrm{X},+3,-4 \mathrm{q} 34 \text {-qter, }+7 \mathrm{q} 21 \text {-q22,-7q32-qter,-8p22-pter, }+8 \mathrm{q} 21 \text {-qter,-10q24-qter, } \\
+11 \mathrm{q} 22 \text {-qter,-15q12-q15,-17,+18,-21q }\end{array}$ & 0 & 1 \\
\hline $40 \mathrm{R} 1$ & 6 & -1 p13-p21,+3q,+12,-13q13-q21,+13q22-q32,+18 & 2 & 0 \\
\hline $40 \mathrm{R} 2$ & 3 & $+3 q,+12,+13 q 22-q 32$ & $\operatorname{lm}$ & $\operatorname{lm}$ \\
\hline
\end{tabular}

$*$ Bold style indicates region with high level amplification.

$\mathrm{D}=$ diagnostic tumor; $\mathrm{R}=$ relapse; $\mathrm{lm}=$ lack of material; classes from immunohistochemistry results concerning BCL2 and BCL6: $0<20 \%, 1=$ $20-80 \%, 2>80 \%$ of cells positively stained.

tween diagnostic tumor sample and relapse indicated separate tumor clones. To confirm the SSCP finding that Tumors 29D and 29R were not clonally related, the PCR products from these samples were sequenced directly using an auto- mated ABI PRISM 377 sequencer (Perkin ElmerCetus, Norwalk, CT). The sequences were then aligned with $I G H$ sequences retrieved from the National Center for Biotechnology Information (www.ncbi.nlm.nih.gov/igblast/). 


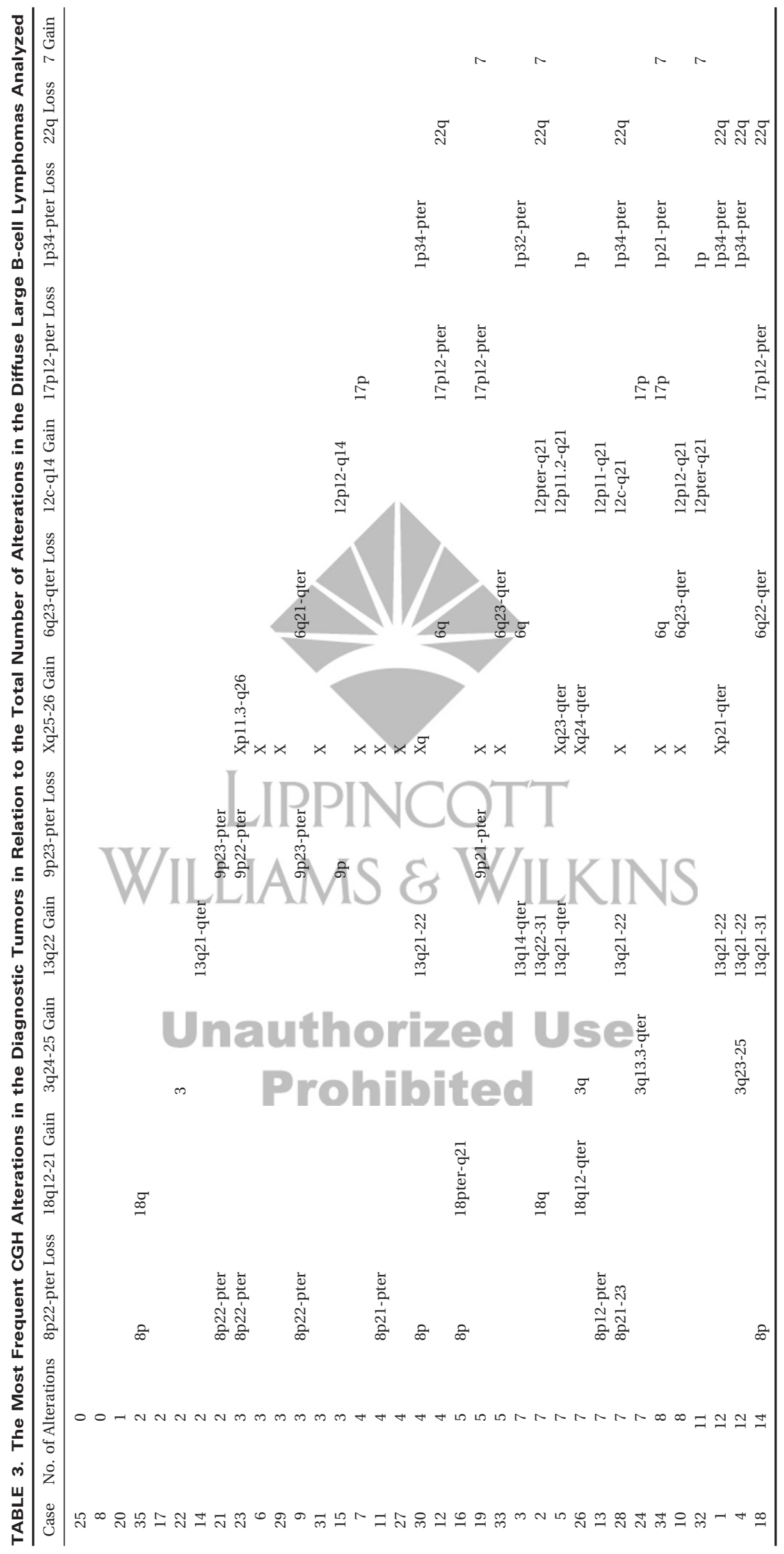


TABLE 4. The Most Frequent CGH Alterations in Diagnostic Tumors in Relation to Relapses

\begin{tabular}{lrcc}
\hline \multicolumn{1}{c}{ Alteration } & $\begin{array}{c}\text { Diagnostic } \\
\text { Tumors }\end{array}$ & Relapses* & $P$ Value \\
\hline Gain Xq25-26 & $15 / 35(43 \%)$ & $9 / 15(60 \%)$ & $\mathrm{ns}$ \\
Loss 8p22-pter & $10 / 35(29 \%)$ & $4 / 15(27 \%)$ & $\mathrm{ns}$ \\
Loss 1p34-pter & $9 / 35(26 \%)$ & $5 / 15(33 \%)$ & $\mathrm{ns}$ \\
Gain 13q22 & $9 / 35(26 \%)$ & $3 / 15(20 \%)$ & $\mathrm{ns}$ \\
Loss 6q23-qter & $7 / 35(20 \%)$ & $7 / 15(47 \%)$ & $\mathrm{ns}$ \\
Loss 22q & $6 / 35(17 \%)$ & $1 / 15(7 \%)$ & $\mathrm{ns}$ \\
Gain 12c-q14 & $7 / 35(20 \%)$ & $6 / 15(40 \%)$ & $\mathrm{ns}$ \\
Loss 17p12-pter & $6 / 35(17 \%)$ & $3 / 15(20 \%)$ & $\mathrm{ns}$ \\
Loss 9p23-pter & $5 / 35(14 \%)$ & $1 / 15(7 \%)$ & $\mathrm{ns}$ \\
Gain 3q24-25 & $4 / 35(11 \%)$ & $4 / 15(27 \%)$ & $\mathrm{ns}$ \\
Gain 7 & $4 / 35(11 \%)$ & $5 / 15(33 \%)$ & $\mathrm{ns}$ \\
Gain 18q12-21 & $4 / 35(11 \%)$ & $6 / 15(40 \%)$ & $P<.02$ \\
Mean number of CGH alterations & 5.1 & 6.3 & $\mathrm{~ns}$ \\
\hline
\end{tabular}

* Refers to 15 cases with in total 19 tumors. Each CGH alteration in subsequent relapses from the same case were counted once.

ns $=$ not significant.

TABLE 5. The Most Frequent CGH Alterations in Diagnostic Tumors of Clinical Stage I-II in Relation to Clinical Stage III-IV

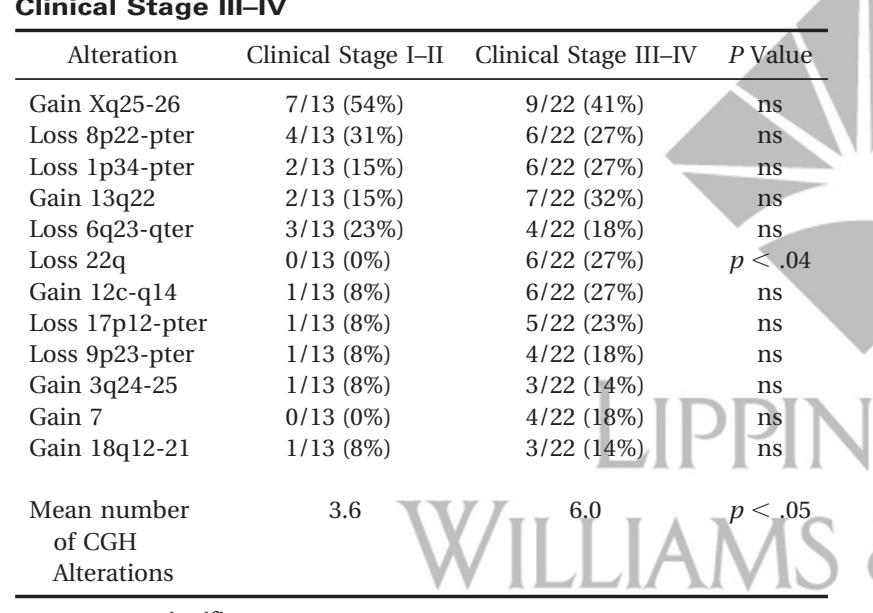

$\mathrm{ns}=$ not significant.

TABLE 6. Estimation of Clonal Relatedness based on IGH-Rearrangements and CGH

\begin{tabular}{ccc}
\hline Tumors & $I G H$-Rearrangements & CGH \\
\hline $26 \mathrm{D}+26 \mathrm{R}$ & Yes & Yes \\
$27 \mathrm{D}+27 \mathrm{R}$ & $\mathrm{nc}$ & No \\
$28 \mathrm{D}+28 \mathrm{R}$ & Yes & Yes \\
$29 \mathrm{D}+29 \mathrm{R}$ & No & No \\
$30 \mathrm{D}+30 \mathrm{R}$ & $\mathrm{nc}$ & Yes \\
$31 \mathrm{D}+31 \mathrm{R}$ & Yes & Yes \\
$32 \mathrm{D}+32 \mathrm{R}$ & $\mathrm{nc}$ & Yes \\
$33 \mathrm{D}+33 \mathrm{R}$ & Yes & Yes \\
$34 \mathrm{D}+34 \mathrm{R}$ & Yes & Yes \\
$35 \mathrm{D}+35 \mathrm{R} 1-3$ & Yes & Yes \\
$40 \mathrm{R} 1+40 \mathrm{R} 2$ & Yes & Yes \\
\hline
\end{tabular}

$\mathrm{D}=$ diagnostic tumor; $\mathrm{R}=$ relapse; $\mathrm{nc}=$ not conclusive.

Immunohistochemistry

Paraffin-embedded sections $(4 \mu \mathrm{m})$ from $46 \mathrm{DL}$ BCL tumors were deparaffinized and rehydrated. BCL2 and BCL6 antigen retrieval was achieved by incubating the sections in $10 \mathrm{~mm}$ sodium citrate buffer (pH 6.0) (20) and 10 mm EDTA buffer (pH 8.0)
(21) separately, and treated within a pressure cooker (Biocare Medical, Walnut Creek, CA) at 103 $\mathrm{kPa} / 15 \mathrm{psi}$ for 7 minutes. Staining was carried out in an automated immunostainer (Ventana 320ES, Ventana Medical Systems, Tucson, AZ) using Ventana basic 3,3'-diaminobenzidine detection kit (Ventana Medical Systems), according to the recommendations of the manufacturer. Briefly, sections were incubated with murine anti-BCL2 (clone 124, DAKO, Glostrup, Denmark) (22) or murine anti-BCL6 (clone PG-B6p, DAKO) (23) monoclonal antibodies (diluted 1/20) for 28 minutes. Immunoreactivity was visualized with avidin-labeled HRPO complex and 3,3 diaminobenzidine followed by counterstaining with Mayer's hematoxylin (Ventana medical systems). All incubations were performed at $37^{\circ} \mathrm{C}$. Incubation with murine $\mathrm{IgG}_{1}$ sera $(20 \mu \mathrm{g} / \mathrm{mL}$, DAKO) was used as a negative control, and BCL2 and BCL6 staining of sections of a reactive tonsil as a positive control. The proportion of positively stained cells was estimated on sections from each tissue biopsy. The results were divided into three classes: Class 0, with $<20 \%$ stained cells; Class 1, with 20 to $80 \%$ stained cells; and Class 2, with $>80 \%$ stained cells. Eight of the 54 tumors (11D, 13D, 19D, 20D, 25D, 34R1, 34R2, and 40R2) could not be analyzed because of lack of material.

\section{Statistical Analyses}

Differences in proportions of CGH alterations were tested with the $\chi^{2}$ test. The distribution of the number of $\mathrm{CGH}$ alterations in different subgroups was investigated with the $t$ test. Probabilities of $<0.05$ were considered statistically significant. The statistical analyses were performed using the Statistica 5.0 software.

\section{RESULTS}

\section{Overview of CGH Alterations in DLBCL}

The CGH karyotypes of each tumor are detailed in Table 2 and the distribution of the detected gains and losses is illustrated in Figure 1A. Copy number changes were identified in 52 of the 54 tumors analyzed (96\%), and gains were more commonly seen than losses. Overall, the subchromosomal regions most frequently gained were Xq25-26 (44\%), 12cen-q14 (28\%), 13q22 (24\%), and 18q12-21 (22\%), whereas losses preferentially involved 1p34-pter (30\%), 8p22-pter (30\%), and 6q23-qter (28\%) (Fig. 1A). None of the recurrent alterations were detected as a single abnormality. High-level amplifications were recorded in 10 tumors from six patients (Table 2 ). The regions $2 \mathrm{p} 13-16$ and $2 \mathrm{q} 22-24$ as well as 8q22-qter and 12pter-q21 were coexisting as highlevel amplifications in one tumor each, whereas 


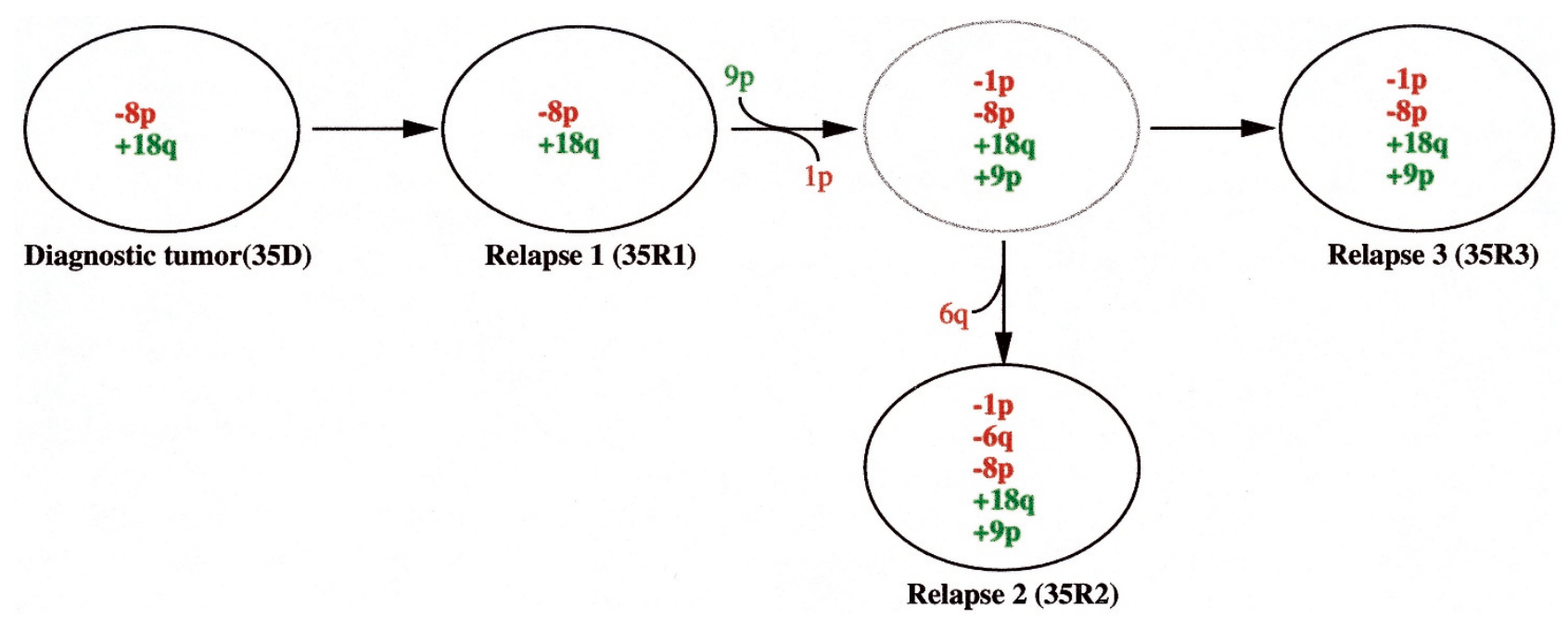

FIGURE 2. Tumor progression in Case 35 based on changes detected by comparative genomic hybridization. The model includes the results from the diagnostic tumor (35D) and the three subsequent relapses (35R1-R3), as well as a hypothetical intermediate tumor (dotted circle). A plus ( + ) indicates chromosomal gains, and a minus $(-)$ denotes losses.

regions 12p11-q21, 13q21-qter, 18q12-qter, and 18q appeared as single high-level amplifications in four cases. The high-level amplifications involving $18 \mathrm{q}$ were identified in two diagnostic tumors and were maintained in the subsequent relapses (Table 2).

Regions from 12 different chromosomes were found to be frequently aberrant in the diagnostic tumors analyzed (Fig. 1B) and in relapses (Fig. 1C). In the diagnostic tumors, commonly gained regions were Xq25-26 (43\%), 13q22 (26\%), 12cen-q14 (20\%), $3 q 24-25$ (11\%), 7 (11\%), and 18q12-21 (11\%), and losses were mainly detected at 8p22-pter (29\%), 1p34-pter (26\%), 6q23-qter, (20\%), 17p12-pter (17\%), 22q (17\%), and 9p23-pter (14\%). In the relapses, gains were mainly observed at Xq25-26 (60\%), 12c-q14 (40\%), 18q12-21(40\%), 7 (33\%), $3 q 24-25$ (27\%), and 13q22 (20\%), whereas losses mainly encompassed 6q23-qter (47\%), 1p34-pter (33\%), 8p22-pter (27\%), and 17p12-pter (20\%). Furthermore, losses of 9p23-pter and $22 \mathrm{q}$ was only found in $5 \%$ of the relapses, whereas a loss of Xq appeared in $21 \%$ of the relapses and only in $3 \%$ of the diagnostic tumors.

In the individual diagnostic tumors the pattern of CGH alterations varied depending on the total number of detected alterations (Table 3). Loss of $8 p$ and $9 p$ and gain of $3 q, 13 q$, and $18 q$ were detected in tumors with only two abnormalities. The most common alteration, that is, gain of $\mathrm{Xq}$, was only seen in tumors with three or more alterations. Similarly, loss of $1 p, 6 q, 17 p$, and $22 q$ and gain of 7 and $12 q$ were detected in cases with three or more alterations only. Taken together, these findings would suggest a progression of genetic events in which they are early but not initiating events in DLBCL tumorigenesis. None of the common alterations were detected as a single abnormality.

\section{CGH Alterations in Diagnostic Tumors} Versus Relapses

The total number of CGH alterations was similar between diagnostic tumors and relapses, and the mean number of alterations in the two groups was 5.1 and 6.3, respectively. When the most frequent alterations in the 35 diagnostic tumors (1D-35D) were compared with the aberrations identified in the 19 relapses (26R-40R) from the 15 cases with one or more relapses (Table 4), a gain of 18q12-21 was significantly more often detected in relapses $(P$ .02). In these analyses, $C G H$ alterations occurring in more than one relapse (34R1-2, 35R $1-3$, and 40R1-2) were counted only once.

\section{CGH Alterations in Relation to Clinical Stage and Sex}

Possible associations between the total number of CGH alterations and most frequent CGH alterations were evaluated in relation to clinical stage, sex, and their presence in diagnostic tumors and relapses. Firstly, the diagnostic tumors were ordered according to increasing clinical stage. This revealed that the total number of CGH alterations was significantly higher among the 22 cases with the most advanced clinical stages (III-IV), compared with the 18 tumors of Stages I and II, and the mean number of CGH alterations in the two groups was 6.0 and 3.6, respectively $(P<.05)$ (Table 5). Loss of chromosome 22q was significantly more common in cases with more advanced clinical stage $(P<.04)$ (Table 5). Notably, all commonly occurring aberrations except gain of $3 q$ and 7 , and loss of $22 q$ were detected already in tumors of Clinical Stage I. Thus, the majority of CGH abnormalities occur early in the clinical progression (not shown). 
No difference in total number CGH alterations was observed between diagnostic tumors from male $(n=28)$ compared with female $(n=12)$ cases. However, when the most commonly involved regions were taken into account, a gain of $13 \mathrm{q}$ showed a tendency to be more frequent in male cases (not shown).

\section{Analyses of Clonal Relatedness}

In 11 cases (Cases 26-35 and 40), multiple DLBCL tumors were obtained and the sequence of CGH alterations were analyzed in subsequent relapses. The clonal relationship between the diagnostic tumor and relapses was also evaluated based on the patterns of $I G H$-rearrangement (Table 6). For three of the 11 cases $(27,30$, and 32$)$, the analyses of $I G H$ rearrangement were not conclusive. In seven cases $(26,28,31,33,34,35$, and 40$)$ the CGH profile was very similar in matched tumors, and the IGH rearrangement analyses showed that subsequent tumors had identical IGH rearrangements. The relapses thus seemed to be derived from the same clone as the diagnostic tumor sample. In Case 30, the diagnostic tumor and the subsequent relapse are also likely to be related based on the similarity of the CGH profiles.

For Case 35, three subsequent relapses were studied in addition to the diagnostic tumor, and based on the CGH alterations identified, a scheme for the tumor progression could be suggested-(Fig. 2). However, in two cases (Cases 27 and 29), there were profound differences in the CGH profiles between the diagnostic tumor and relapse, and in Case 29 also a different $I G H$-rearrangement in the relapse could be confirmed, thus indicating that the relapses in these cases were not clonally related to the diagnostic tumors (Table 6). In both of these cases the time interval between diagnosis and relapse was approximately 1 year.

\section{Immunohistochemistry and CGH}

Thirty of the analyzed samples were diagnostic tumors, and 16 were relapses (Table 2). No significant association was observed between a gain of $3 q 27$ and the level of BCL6 expression. A high-level amplification of 18q21 was recorded in six of the tumors (26D, 26R, 35D, 35R1, 35R2, and 35R3), and each sample showed a Class 2 expression of BCL2 (Table 2). In nine of the analyzed tumors (six diagnostic tumors and three relapses) with Class 2 expression of BCL2 we could not, by CGH, detect a gain of 18q (Table 2).

\section{DISCUSSION}

In this study, we identified several frequently occurring CGH alterations in DLBCL. In agreement with previous studies $(5,24-26)$, recurrent changes were gains of $X, 3 q, 7,12 q$, and 18q, whereas $6 q$, and $17 p$ were frequently lost. In addition, previously not-reported losses of $1 p, 8 p, 9 p$, and $22 q$ and gain of $13 q$ were identified as frequent. There was a tendency toward an increased number of changes in relapses compared with diagnostic tumors, and chromosomal imbalances were identified in $94 \%$ of the diagnostic tumor samples and in all off the relapses.

The concordance between chromosomal changes in DLBCL identified by G-banding and the alterations detected by CGH is in general good (24). However, the cytogenetic evidence, such as double-minutes (DM) or homogeneously staining regions (HSR), for CGHdetected high-level amplifications is scarce (24). This higher sensitivity to detect an increase of genetic material could be explained by the fact that the CGH technique scans the DNA of the entire tumor including all cellular subclones. Banding analysis requires cell culturing that is known to favor growth of certain cell populations (27), whereby cells carrying DM may remain undetected because they lack functional centromeres. Twenty percent of the tumors in this series exhibiting a chromosomal gain carried a high-level amplification. The most likely cytogenetic mechanism behind these amplifications is DM, because DM is the main cytogenetic manifestation of gene amplification in noncultured cells taken directly from patients (28), such as the tumor biopsies used in this study.

In agreement with a previous CGH study on DLBCL (5), high-level amplifications were most frequently found at the distal part of the long arm of chromosome 18 with a minimal region of 18q12-21. In the present study, all cases with high-level amplification of 18q21 also showed Class 2 expression of $B C L 2$. This suggests that gene amplification, in these cases, could be the mechanism for increased expression of BCL2; however, it does not exclude the possibility of a coexisting BCL2 involving translocation such as the $t(14 ; 18)$, which also increases the gene expression. The $(14 ; 18)$-translocation is the most likely mechanism behind high BCL2 expression in those tumors lacking a gain of 18q21. The gain of minimal region 18q12-21 was significantly more common in relapses than in diagnostic tumors $(P<.02)$; however, there was no significant difference concerning the BCL2 expression between diagnostic tumors and relapses carrying a gain of 18q12-21. An increased level of BCL2 expression has been reported to appear as an early event in tumor progression (29) and an upregulation of BCL2 as a result of a $t(14 ; 18)$ is considered to be the primary event in follicular B-cell lymphomas (30). Thus other genes than BCL2 located in this chromosomal region might be involved in the progression of DLBCL. 
Loss of $22 \mathrm{q}$ was significantly more common in cases with clinically more advanced stage of the disease (Stages III-IV compared with Stages I-II; $P$ $<.04$ ), and one possible explanation for this finding may be loss of the G22P1 gene at $22 \mathrm{q} 13$ that is encoding for the $\mathrm{Ku} 70$ protein. Ku70 heterodimerizes with Ku80 to form a protein kinase that is essential in both the repair of double-stranded DNA breaks (DSBs) and in the V(D)J recombination (3133). Tumor cells with a deficient mechanism for DSB repair would result in cells with more chromosomal imbalances and a more advanced disease. However, $>600$ genes are located to the long arm of chromosome 22 (J. Dumanski, personal communication). Some have been excluded to play an important role in the DLBCL tumorigenesis, such as the cell cycle regulator gene CHK2 (34).

None of the recurrent alterations were detected as a single abnormality (Table 3 ), which implies that other genetic lesions below the detection level of CGH may be involved in the initiation of DLBCL. It has recently been suggested that an aberrant somatic hypermutation mechanism may play an important role for the pathogenesis in these neoplasias (35). Such dysregulated hypermutation machinery would increase the occurrence of chromosomal aberrations as well as it would result in mutations of numerous genes with consequences analogous to defects in DNA mismatch repair in colon cancer (36). Our results of relatively spread CGH events support the concept about an aberrant somatic hypermutation mechanism in DLBCL that also would explain the clinical heterogeneity of the disease.

Earlier studies on lymphoma have shown that disease progression could either be clonally related or represent clonally unrelated neoplasms $(37,38)$. Clonally unrelated relapses are uncommon but have been reported $(37,38)$. Treatment may induce changes that are responsible for the formation of new neoplasms in patients. Two of the 11 cases $(27$ and 29) analyzed with multiple DLBCL tumors had relapses that did not seem to be clonally related to the diagnostic tumor sample. The time interval between the diagnostic tumor and relapse was in both cases short, which makes therapy-induced lymphomas less likely. From the CGH analysis of Case 35, we could follow the development from the diagnostic tumor to the third relapse, and we observed that the tumor progression was not cytogenetically linear (Fig. 2). From this, we propose that even if patients are in complete remission clinically, the original lymphoma-causing clone may give rise to one or more subclones that did not respond to the given treatment. To irradiate these dormant clones, new complementary treatment should be used in addition to traditional therapies.
The distribution of CGH alterations supports the idea of a progression of genetic events in which loss of $8 p$ and $9 p$ and gain of $3 q, 13 q$, and $18 q$ would represent relatively early events because they were distributed in tumors with the lowest number of abnormalities. However, none of the recurrent alterations were detected as a single abnormality, indicating that none of these represent the initiating event in the tumorigenesis of DLBCL. These could constitute balanced rearrangements or discrete alterations that would remain undetected by CGH. In conclusion, the clinical and histopathological diversity of DLBCL is paralleled by a similarly complex genetic background of primary events. Some of the recurrent alterations identified in our study are expected to be involved in tumor progression, thus providing possible new genetic markers of prognostic significance.

Acknowledgments: The authors wish to thank Dr. Soili Kytölä for technical advice and Lila Shokoideh for technical assistance.

\section{REFERENCES}

1. Harris NL, Jaffe ES, Stein H, Banks PM, Chan JK, Cleary ML, et al. A revised European-American classification of lymphoid neoplasms: a proposal from the International Lymphoma Study Group. Blood 1994;84:1361-92.

2. Cigudosa JC, Parsa NZ, Louie DC, Filippa DA, Jhanwar SC, Johansson B, et al. Cytogenetic analysis of 363 consecutively ascertained diffuse large B-cell lymphomas. Genes Chromosomes Cancer 1999;25:123-33.

3. Project/TIN-HsLPF. A predictive model for aggressive nonHodgkin's lymphoma. N Engl J Med 1993;329:987-94.

4. Mitelman F. Catalog of chromosome aberrations in cancer, 1998. New York: John Wiley \& Sons; 1998.

5. Monni O, Joensuu H, Franssila K, Knuutila S. DNA copy number changes in diffuse large B-cell lymphoma-comparative genomic hybridization study. Blood 1996;87:526978.

6. Skinnider BF, Horsman DE, Dupuis B, Gascoyne RD. Bcl-6 and Bcl-2 protein expression in diffuse large B-cell lymphoma and follicular lymphoma: correlation with 3q27 and 18q21 chromosomal abnormalities. Hum Pathol 1999;30:803-8.

7. Lo Coco F, Ye BH, Lista F, Corradini P, Offit K, Knowles DM, et al. Rearrangements of the BCL6 gene in diffuse large cell non-Hodgkin's lymphoma. Blood 1994;83:1757-9.

8. Dalla-Favera R, Ye BH, Lo Coco F, Gaidano G, Lista F, Knowles DM, et al. Identification of genetic lesions associated with diffuse large-cell lymphoma. Ann Oncol 1994;5:5560 .

9. Monni O, Joensuu H, Franssila K, Klefstrom J, Alitalo K, Knuutila S. BCL2 overexpression associated with chromosomal amplification in diffuse large B-cell lymphoma. Blood 1997;90:1168-74.

10. Bastard C, Deweindt C, Kerckaert JP, Lenormand B, Rossi A, Pezzella F, et al. LAZ3 rearrangements in non-Hodgkin's lymphoma: correlation with histology, immunophenotype, karyotype, and clinical outcome in 217 patients. Blood 1994; 83:2423-7.

11. Cattoretti G, Chang CC, Cechova K, Zhang J, Ye BH, Falini B, et al. BCL-6 protein is expressed in germinal-center B cells. Blood 1995;86:45-53. 
12. Onizuka T, Moriyama M, Yamochi T, Kuroda T, Kazama A, Kanazawa N, et al. BCL-6 gene product, a 92-to 98-kD nuclear phosphoprotein, is highly expressed in germinal center B cells and their neoplastic counterparts. Blood 1995;86:2837.

13. Bajalica-Lagercrantz S, Piehl F, Lagercrantz J, Lindahl J, Weber G, Kerckeart JP, et al. Expression of LAZ3/BCL6 in follicular center (FC) B cells of reactive lymph nodes and FCderived non-Hodgkin lymphomas. Leukemia 1997;11:594-8.

14. Kallioniemi A, Kallioniemi OP, Sudar D, Rutovitz D, Gray JW, Waldman $\mathrm{F}$, et al. Comparative genomic hybridization for molecular cytogenetic analysis of solid tumors. Science 1992; 258:818-21.

15. du Manoir S, Speicher MR, Joos S, Schrock E, Popp S, Dohner $\mathrm{H}$, et al. Detection of complete and partial chromosome gains and losses by comparative genomic in situ hybridization. Hum Genet 1993;90:590-610.

16. Li AH, Rosenquist R, Forestier E, Holmberg D, Lindh J, Lofvenberg E, et al. Clonal rearrangements in childhood and adult precursor B acute lymphoblastic leukemia: a comparative polymerase chain reaction study using multiple sets of primers. Eur J Haematol 1999;63:211-8.

17. Rosenquist R, Thunberg U, Li AH, Forestier E, Lonnerholm $\mathrm{G}$, Lindh J, et al. Clonal evolution as judged by immunoglobulin heavy chain gene rearrangements in relapsing precursor-B acute lymphoblastic leukemia. Eur J Haematol 1999;63:171-9.

18. Alemi M, Andersson S, Sallstrom J, Wilander E. Rapid test for identification of a human papillomavirus 16 E6 L83V variant. Diagn Mol Pathol 1999;8:97-100.

19. Rosenquist R, Linderholm B, Lindstrom A, Hagberg H, Sundstrom C, Roos G, et al. Alterations of the immunoglobulin heavy chain locus in progressive B-cell lymphomas. Acta Oncol 1998;37:193-200.

20. Szekeres G. Detection of the Ki-67 antigen in fixed proliferating cells [letter]. Anal Cell Pathol 1993;5:249-50.

21. Morgan JM, Navabi H, Schmid KW, Jasani B. Possible role of tissue-bound calcium ions in citrate-mediated hightemperature antigen retrieval. J Pathol 1994;174:301-7.

22. LeBrun DP, Kamel OW, Cleary ML, Dorfman RF, Warnke RA. Follicular lymphomas of the gastrointestinal tract. Pathologic features in 31 cases and bcl-2 oncogenic protein expression. Am J Pathol 1992;140:1327-35.

23. Flenghi L, Bigerna B, Fizzotti M, Venturi S, Pasqualucci L, Pileri S, et al. Monoclonal antibodies PG-B6a and PG-B6p recognize, respectively, a highly conserved and a formolresistant epitope on the human BCL-6 protein aminoterminal region. Am J Pathol 1996;148:1543-55.

24. Rao PH, Houldsworth J, Dyomina K, Parsa NZ, Cigudosa JC Louie DC, et al. Chromosomal and gene amplification in diffuse large B-cell lymphoma. Blood 1998;92:234-40.
25. Rickert CH, Dockhorn-Dworniczak B, Simon R, Paulus W. Chromosomal imbalances in primary lymphomas of the central nervous system. Am J Pathol 1999;155:1445-51.

26. Chan WY, Wong N, Chan AB, Chow JH, Lee JC. Consistent copy number gain in chromosome 12 in primary diffuse large cell lymphomas of the stomach. Am J Pathol 1998;152: $11-6$.

27. Nordgren A, Schoumans J, Soderhall S, Nordenskjold M, Blennow E. Interphase fluorescence in situ hybridization and spectral karyotyping reveals hidden genetic aberrations in children with acute lymphoblastic leukaemia and a normal banded karyotype. Br J Haematol 2001;114:786-93.

28. Benner SE, Wahl GM, Von Hoff DD. Double minute chromosomes and homogeneously staining regions in tumors taken directly from patients versus in human tumor cell lines. Anticancer Drugs 1991;2:11-25.

29. Wilson WH, Teruya-Feldstein J, Fest T, Harris C, Steinberg SM, Jaffe ES, et al. Relationship of p53, bcl-2, and tumor proliferation to clinical drug resistance in non-Hodgkin's lymphomas. Blood 1997;89:601-9.

30. Lopez-Guillermo A, Cabanillas F, McDonnell TI, McLaughlin $\mathrm{P}$, Smith T, Pugh W, et al. Correlation of bcl-2 rearrangement with clinical characteristics and outcome in indolent follicular lymphoma. Blood 1999;93:3081-7.

31. Muller C, Dusseau C, Calsou P, Salles B. Human normal peripheral blood B-lymphocytes are deficient in DNAdependent protein kinase activity due to the expression of a variant form of the Ku86 protein. Oncogene 1998;16:155360.

32. Li GC, Ouyang H, Li X, Nagasawa H, Little JB, Chen DJ, et al. Ku70: a candidate tumor suppressor gene for murine $\mathrm{T}$ cell lymphoma. Mol Cell 1998;2:1-8.

33. Brown KD, Lataxes TA, Shangary S, Mannino JL, Giardina JF, Chen $\mathrm{J}$, et al. Ionizing radiation exposure results in upregulation of Ku70 via a p53/ataxia-telangiectasia-mutated protein-dependent mechanism. J Biol Chem 2000;275:6651-6.

34. Tavor S, Takeuchi S, Tsukasaki K, Miller CW, Hofmann WK, Ikezoe T, et al. Analysis of the CHK2 gene in lymphoid malignancies. Leuk Lymphoma 2001;42:517-20.

35. Pasqualucci L, Neumeister $P$, Goossens $T$, Nanjangud G, Chaganti RS, Kuppers R, et al. Hypermutation of multiple proto-oncogenes in B-cell diffuse large-cell lymphomas. Nature 2001;412:341-6.

36. Lengauer C, Kinzler KW, Vogelstein B. Genetic instabilities in human cancers. Nature 1998;396:643-9.

37. Matolcsy A. High-grade transformation of low-grade nonHodgkin's lymphomas: mechanisms of tumor progression. Leuk Lymphoma 1999;34:251-9.

38. Muller-Hermelink HK, Zettl A, Pfeifer W, Ott G. Pathology of lymphoma progression. Histopathology 2001;38:285-306. 


\section{Book Review}

Grossbard ML: American Cancer Society Atlas of Clinical Oncology: Malignant Lymphomas, 468 pp, Hamilton, Ontario, Canada, B.C. Decker Inc., 2001 (\$149.00).

This is a multi-authored book published in a series sponsored by the American Cancer Society. It deals with the recent advances in the pathology, epidemiology, molecular biology, clinical presentations, and management of malignant lymphomas. Clinical aspects of lymphoma diagnosis and therapeutics form the backbone of the book, but adequate space is reserved for the discussion of pathology and molecular biology and other facets of neoplastic diseases of the lymphopoietic system.

This book is aimed primarily at clinical oncologists in general and oncologic hematologists in particular. Topics such as staging of lymphomas and Hodgkin disease, prognostic factors, chemotherapy, transplantation, and radiation therapy as well as immunotherapy are dealt with in detail. Recommendations for treatment are based on contributors' personal experiences supported by data from recent literature. The text is supplemented with numerous summary tables and graphs illustrating the treatment outcomes. The references are up-to date and many are from 2000 and even 2001.

The pathologic features of various lymphomas are illustrated in color photographs. Many of these photographs are of substandard quality and essentially uninterpretable, which is a pity. A CD-ROM containing the entire text and all of the pictures is included with the book, but the illustrations on the disc are not any better than those in the book.

Like the other books in this ACS series, this book will be used mostly by clinicians. Nevertheless, pathologists interested in lymphomas and Hodgkin disease also will find enough valuable material between its covers.

Marin Nola

University of Zagreb School of Medicine Zagreb, Croatia

\section{LIPPINCOTT WILLIAMS \& WILKINS}

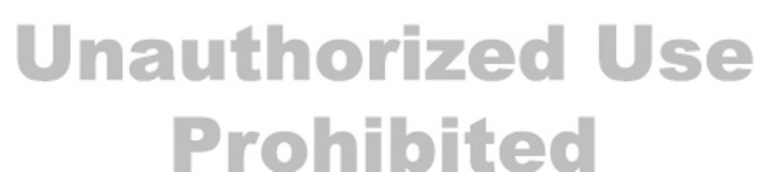

